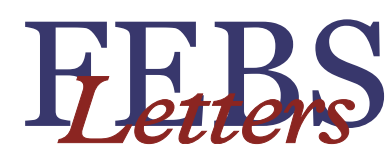

journal homepage: www.FEBSLetters.org

\title{
SKIP is required for TGF- $\beta 1$-induced epithelial mesenchymal transition and migration in transformed keratinocytes
}

\author{
Victor Villar $^{\mathrm{a}}$, Jelena Kocic ${ }^{\mathrm{b}}$, Diana Bugarski ${ }^{\mathrm{b}}$, Gordana Jovcic ${ }^{\mathrm{b}}$, Juan F. Santibanez ${ }^{\mathrm{a}, \mathrm{b}, *}$ \\ ${ }^{a}$ Laboratorio de Biología Celular, Instituto de Nutrición y Tecnología de los Alimentos, Universidad de Chile, Santiago, Chile \\ ${ }^{\mathrm{b}}$ Laboratory for Experimental Hematology, Institute for Medical Research, University of Belgrade, Dr. Subotica 4, P.O. Box 102, 11129 Belgrade, Serbia
}

\section{A R T I C L E I N F O}

\section{Article history:}

Received 21 June 2010

Revised 4 October 2010

Accepted 11 October 2010

Available online 19 October 2010

Edited by Lukas Huber

\section{Keywords:}

Transforming growth factor- $\beta 1$

Sky-interacting protein

Epithelial-mesenchymal transition

Urokinase type plasminogen activator

Plasminogen activator inhibitor type- 1

Migration

\begin{abstract}
A B S T R A C T
Transforming growth factor- $\beta 1$ (TGF- $\beta 1$ ) potently induces the epithelial-mesenchymal transition (EMT) during tumoral progression. Although Sky-interacting protein (SKIP) regulates TGF-p1induced Smad activation, its role in the induction of cell malignance remains uncertain. We found that TGF- $\beta 1$ increases SKIP expression in PDV cells. In cells stably transfected with SKIP antisense, AS-S, Smad3 activation decreased, along with an inhibition of TGF-p1-induced EMT, and the cells were sensitized to the TGF-ß1-dependent inhibition of proliferation. Also, AS-S cells showed a weaker migration and invasion response. Moreover, TGF- $\beta 1$-induced urokinase-type plasminogen activator expression was inhibited, concomitantly with a TGF-p1-independent increment of the plasminogen-activator inhibitor-1 expression. Thus, these results suggest that SKIP is required for EMT and invasiveness induced by TGF- $\beta 1$ in transformed cells.
\end{abstract}

๑) 2010 Federation of European Biochemical Societies. Published by Elsevier B.V. All rights reserved.

\section{Introduction}

The Transforming growth factor- $\beta 1$ (TGF- $\beta 1$ ) super-family of factors is implicated in the regulation of cell proliferation, differentiation, apoptosis, migration, and epithelial-mesenchymal transition (EMT). EMT is important during embryonic development, and also has a role in malignancy as it favours tumour cell invasion and metástasis [1,2]. TGF- $\beta 1$ at early stages of carcinogenesis inhibits tumorigenesis by acting as a tumour suppressor. However, in later steps, TGF- $\beta 1$ stimulates malignant progression in tumour cells that have attenuated or lost the TGF- $\beta 1$ growth inhibitory response $[3,4]$. TGF- $\beta 1$ binds to the functional complex of TGF- $\beta$ family of cell surface receptors and activates Smad2,3 and Smadindependent signals such as ERK1,2 MAPK [5].

As recently reported, Sky-interacting protein (SKIP) interacts with Smad2,3 to augment the TGF- $\beta 1$-dependent transcription, suggesting that SKIP plays a role in the regulation of cell growth and differentiation through the TGF- $\beta$ pathway [6]. SKIP was originally isolated as a putative co activator protein which interacts

\footnotetext{
Abbreviations: TGF- $\beta 1$, transforming growth factor- $\beta 1$; EMT, epithelial-mesenchymal transition; SKIP, Sky-interacting protein; PAI-1, plasminogen activator inhibitor type-1; uPA, urokinase type plasminogen activator

* Corresponding author at: Laboratory for Experimental Research, Institute for Medical Research, University of Belgrade, Dr. Subotica 4, P.O. Box 102, 11129 Belgrade, Serbia. Fax: +381 112643691.

E-mail address: jfsantibanez@imi.bg.ac.rs (J.F. Santibanez).
}

with VDR and v-Ski proto-oncogene using yeast 2-hybrid screening strategies [7,8]. SKIP is a well-conserved transcriptional adaptor protein which, depending on the cellular context, functions to recruit either activation or repression complexes to mediate multiple signaling pathways involved in the control of cell proliferation and differentiation [9]. Potential function of the SKIP-Ski complex is to overcome the growth-suppressive activities of retinoblastoma protein [10]. In addition, SKIP is upregulated by estradiol-17beta and promotes anchorage-independent growth in ovarian carcinoma cells [11]. However, its precise role in stimulation of tumorigenesis by TGF- $\beta 1$ is poorly understood.

In this research, it was analyzed whether SKIP regulates TGF$\beta 1$-enhanced EMT and invasiveness of transformed cells. We found that the depletion of SKIP by antisense strategy blocks the induction of EMT and cell migration, altogether with the inhibition of urokinase-type plasminogen activator (uPA) system by TGF- $\beta 1$ and enhances plasminogen activator inhibitor type-1 (PAI-1) expression. These results allow us to suggest a critical role for SKIP in the enhancement of malignance by TGF- $\beta 1$ in transformed cells.

\section{Materials and methods}

\subsection{Plasmids and antibodies}

Mouse pREP4 (Antisense mouse SKIP) was kindly provided by Dr. D. Haywars, John Hopkins University School of Medicine, 
USA. The promoter of PAI-1, p-800-luc (+71 to -800) was kindly provided by Dr. C. Bernabeu (CIB, Spain). CAGAC-luc reporter was kindly provided by Dr. P. Ten Dijke (LUMC, The Netherlands). pGL3-E2F reporter with $4 \times$ E2F sites was kindly provided by Dr. Jianrong Lu, University of Florida College of Medicine (USA).

The SKIP rabbit antibody (C-15) was purchased from Santa Cruz Biotechnology, CA. Anti-HA, anti-E-cadherin, anti-fibronectin, antivimentin, anti- $\alpha$-tubulin and secondary antibodies-coupled with HPO or FITC were from Sigma (St. Louis, MO). Anti ZO-1 antibody was from Cell Signalling Technology Inc. (Danvers, MA). Antip-Smad3 and anti-Smad2/3 antibodies were purchased from Calbiochem (Darmstadt, Germany).

\subsection{Cell culture and transfection procedures}

PDV cells, kindly provided by Dr. M. Quintanilla, IIB-CSIC, Spain, were cultured in Ham's F-12 medium supplemented with amino acids and vitamins in the presence of $10 \%$ fetal bovine serum (FBS) and antibiotics. For TGF- $\beta$ treatments, human recombinant TGF- $\beta 1$ (R\&D Systems $\mathrm{GmbH}$, Germany) was used at $5 \mathrm{ng} / \mathrm{ml}$.

For stable transfections, $\sim 10^{6}$ cells seeded on $60 \mathrm{~mm}$ plates were transfected with $5 \mu \mathrm{g}$ of either antisense mouse-SKIP plasmid or empty pCDNA3 vector using Superfect (Qiagen, Hilden, Germany) following the manufacturer's instructions. Transfected cells were selected by growing in medium containing 10\% FBS and $400 \mu \mathrm{g} / \mathrm{ml}$ of G418 for 2 weeks. Individual clones were isolated by cloning rings.

Transient transfections to analyze PAI-1 promoter activity and E2F-luc and CAGAC-luc transactivation were performed as previously described [12]. Firefly luciferase activity (Promega, Adison WI, USA) was standardized for $\beta$-galactosidase activity (Tropix, Bedford, MA, USA).

\subsection{Immunofluorescence and immunoblotting}

E-cadherin, fibronectin, vimentin, and ZO-1 were detected by immunofluorescence and Western blot assays as previously described [13].

\section{4. $R T-P C R$}

Two micrograms total RNA isolated from PDV/M and AS-S cells was reverse transcribed with Superscript II (Invitrogen, Carlsbad, CA). PCR products were obtained after 30-35 cycles of amplification with an annealing temperature of $55-60^{\circ} \mathrm{C}$.

The primer sets used were as follows:

5'-ATC-CTG-CCT-AAG-TTC-TCT-CTG-3',

5'-ATT-GTC-TCT-GTC-GGG-TTG-TG-3', PAI-I (300 bp);

5'-TGC-CCA-AGG-AAA-TTC-TGC-CCA-AGG-AAA-TTC-CAC-GC-3',

5'-GCC-AAT-CTG-CAC-ATA-GCA-CC-3', uPA (280 bp);

5'-TTC-CAC-CGA-ATG-GCT-TCC-AG-3',

5'-AGG-CAA-TGA-GGC-TGA-GTT-GAG-C-3', uPAR (240 bp);

5'-CGT-GAT-GAA-GGT-CTC-AGC-C-3'

5'-ATG-GGG-GCT-TCA-TTC-AC-3', m-E-cadherin (650 bp);

5'-CCC-AGA-CTT-ATG-GTG-GCA-ATT-3',

5'-AAT-TTC-CGC-CTC-GAG-TCT-GA-3', fibronectin (220 bp);

5'-CTG-GAG-AAG-AGC-TAC-GAA-CTG-3',

5'-GGT-TGG-CAG-AGG-CAGA-GAA-AT-3', vimentin (790 bp);

5'-GCA-GCT-GGC-CAG-GCT-CTC-GGT-GG-3'

5'-GTA-GCT-GGG-TCA-GCG-AGG-GCC-TCC-3', Snail (400 bp);

5'-ACC-ACAG-TCC-ATG-CCA-TCA-C-3',

5'-TCC-ACC-ACC-CTG-TTG-CTG-TA-3', GAPDH ( 480 bp).

\subsection{Migration, invasion and zymographic assays}

The motility properties of cell transfectants were analyzed by an in vitro wound healing assay. Wounded cell cultures were allowed to grow for $24 \mathrm{~h}$ in the absence or presence of TGF- $\beta 1$. The capacity of the cells to invade Matrigel-coated filters was assayed as described elsewhere [14]. Urokinase type plasminogen activator (UPA) activity was assayed in a serum-free medium conditioned for $24 \mathrm{~h}$ in cell cultures treated or not with TGF- $\beta 1$ subjected to SDSPAGE and casein-zymography, as reported [14].

\subsection{Proliferation assay}

$5 \times 10^{3}$ cells were seeded in 96 well plates, and treated with different amounts of TGF- $\beta 1$ for $48 \mathrm{~h}$. 3-(4,5-Dimethylthiazol2-yl)-2,5-diphenyltetrazolium bromide (MTT) at $0.5 \mathrm{mg} / \mathrm{ml}$ final concentration was added to each well, after $2 \mathrm{~h}$ the formazan crystals were dissolved with DMSO:isopropanol (2:3) and the absorbance determined at $570 \mathrm{~nm}$ in a plate reader.

\subsection{Statistics}

Data are given as means \pm S.D. from at least three independent experiments. When necessary, statistical significance was evaluated using the Students' $t$-test. Differences $\left({ }^{*}, \&\right)$ were considered to be significant at a value of $P<0.005$.

\section{Results}

3.1. Effect of TGF- $\beta 1$ on SKIP expression in PDV cells and antisense SKIP clones characterization

TGF- $\beta 1$ treatment for different periods of time increased SKIP expression in PDV cells, as determined by Western blot (Fig. 1A). To elucidate whether SKIP has a role in the enhancement of cell malignity by TGF- $\beta 1$, PDV cells were stably transfected with a SKIP antisense construction. Fig. 1B shows two clones with reduced expression of SKIP, designated as AS-S, in comparison with control PDV/Mock (PDV/M) cells. Having established that TGF- $\beta 1$ enhances SKIP expression, we further investigated whether SKIP depletion modulates Smad3 signaling in PDV cells. Fig. 1C shows an inhibition and shorter duration of TGF- $\beta 1$-induced Smad3 phosphorylation in AS-S cells compared with control cells. In addition, using the specific Smad3 reporter, CAGAC-luc, we found that AS-S cells have lower transcriptional activity of Smad3 after TGF- $\beta 1$ treatment compared with PDV/M control cells (Fig. 1D).

\subsection{SKIP modulates TGF- $\beta 1$-induced epithelial mesenchymal transition of PDV cells}

Chronic exposure of PDV cells to TGF- $\beta 1$ induces cell scattering during the first week of treatment followed by a complete EMT [15]. Therefore, we analyzed whether SKIP is required for TGF$\beta 1$-induced EMT. Cells were treated with TGF- $\beta 1$ for 3 days and the changes related with EMT were assessed. As shown in Fig. $2 \mathrm{~A}$, in PDV/M cells TGF- $\beta 1$ : induced delocalization/downregulation of E-cadherin (E-Cad) ( $a$ and b) and ZO-1 (e and f); induced deposition of fibronectin ( $i$ and $j$ ); and enhanced the expression of vimentin ( $\mathrm{m}$ and $\mathrm{n}$ ). Whereas in AS-S cells TGF- $\beta 1$ : disabled delocalization of E-Cad (c and d) and ZO-1 ( $\mathrm{g}$ and $\mathrm{h}$ ); decreased the expression of fibronectin ( $k$ and $\mathrm{l}$ ) and vimentin ( $\mathrm{o}$ and $\mathrm{p}$ ), as determined by immunofluorescence assays. These results, were confirmed by RT-PCR and Western blot analyses (Fig. 2B and C): AS-S cells did not respond to TGF- $\beta 1$ treatment, the expression of E-cadherin, fibronectin, and vimentin were not enhanced in com- 

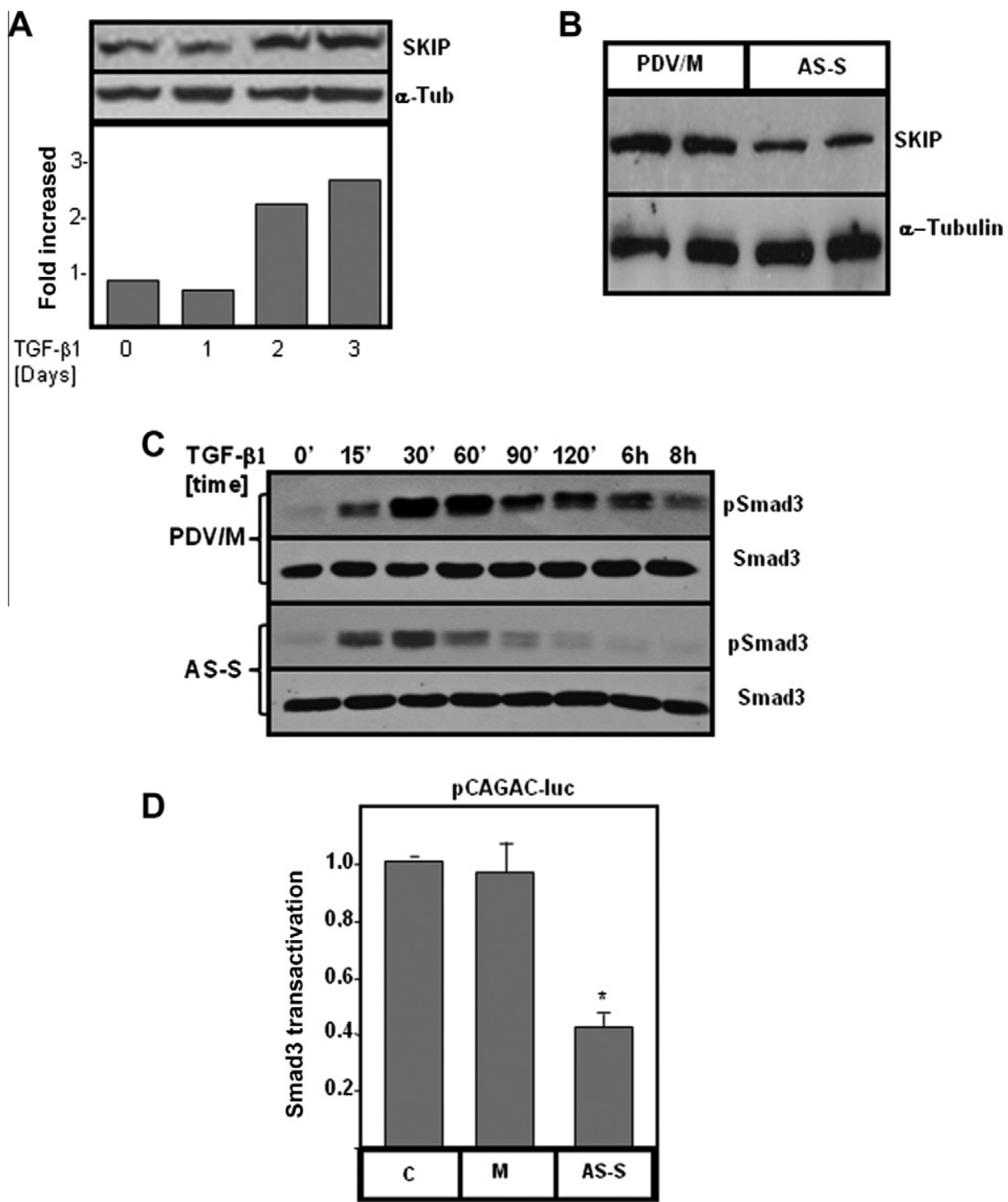

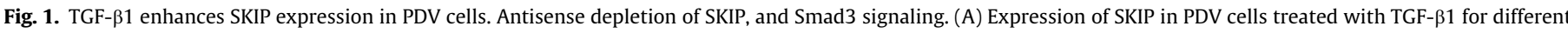

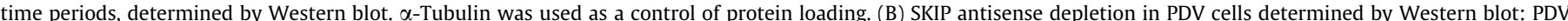

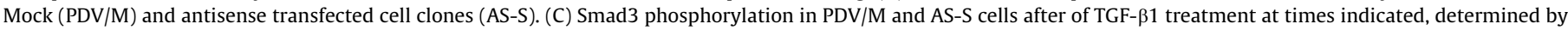

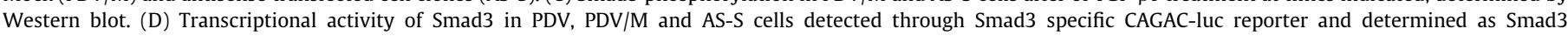
transactivation after TGF- $\beta 1$ treatment compared with the basal level.

parison to control cells; moreover, the expression of E-cadherin transcriptional repressor Snail, which has also been found to be involved in EMT [16], was strongly inhibited in AS-S cells.

\subsection{SKIP depletion sensitises PDV cells to the TGF- $\beta 1$-induced} inhibition of cell proliferation and reduces cell migration and invasion

The downregulation of SKIP in PDV cells enhanced their sensibility to low concentrations of TGF- $\beta 1(0.1-1 \mathrm{ng} / \mathrm{ml})$ which resulted in stronger inhibition of proliferation. At relatively high concentrations of TGF- $\beta 1$ (more than $1 \mathrm{ng} / \mathrm{ml}$ ) a similar inhibition of proliferation was observed in both cell clones (Fig. 3A). Also, AS$S$ cells in basal conditions proliferate slower than PDV/M control cells (Fig. 3A, insert). Given that it was demonstrated that SKIP can overcome the $\mathrm{Rb}$ inhibition of cell proliferation [11], we further explored whether SKIP depletion modulates the activity of the cell cycle regulator E2F, which in turn is regulated by $\mathrm{Rb}$. As an experimental approach a luciferase reporter construct containing response elements to E2F was used. In the absence of TGF- $\beta 1$, AS-S cells showed lower E2F activity compared to control cells, and no difference in TGF- $\beta 1$-induced inhibition of E2F transactivation was observed between AS-S and control cells (Fig. 3B).

Since EMT is associated with enhanced cell migration and invasiveness [1,2], it was further tested whether SKIP is necessary for TGF- $\beta 1$-induced cell motility, using a wound healing assay. While untreated PDV/M cells were unable to close the wound area, the TGF- $\beta 1$-stimulated cells closed it completely. In contrast, TGF$\beta 1$-stimulated cell motility was strongly inhibited in AS-S cells (Fig. 3C). Finally, AS-S cells displayed reduced cell invasiveness through the reconstituted basal membrane Matrigel after a three-day treatment with TGF- $\beta 1$ compared to PDV/M control cells (Fig. 3D).

\subsection{SKIP modulates UPA and PAI-1 expression}

We have previously shown that TGF- $\beta 1$ promotes the expression of uPA associated with the stimulation of invasive properties in PDV cells [14]. In order to analyze whether SKIP is involved in TGF- $\beta 1$-induced UPA expression, the secretion of uPA activity in the conditioned media of both cell clones was studied. As shown 


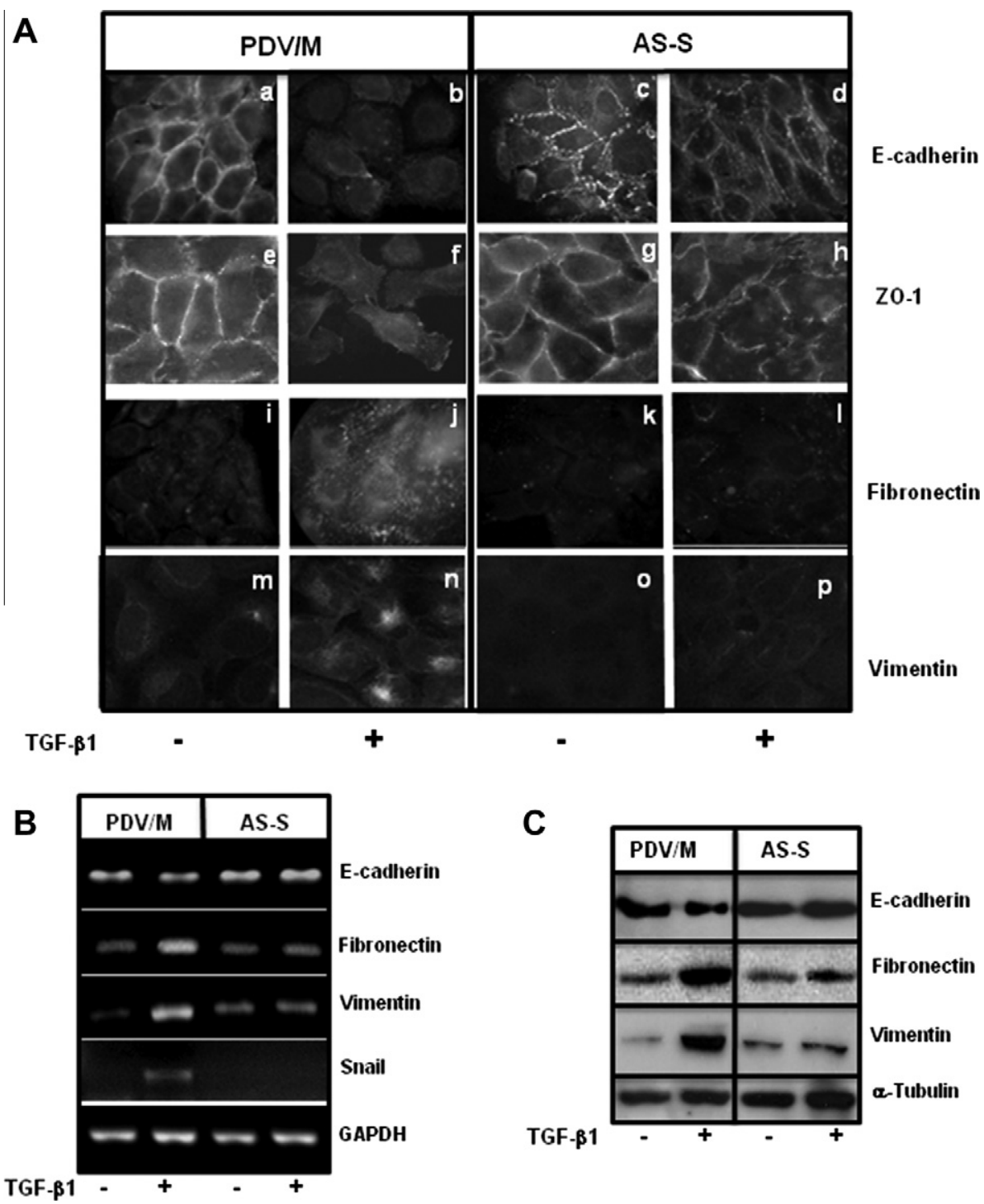

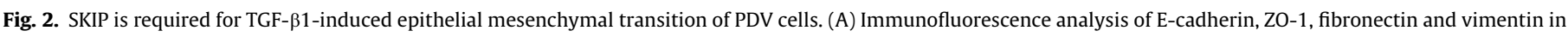

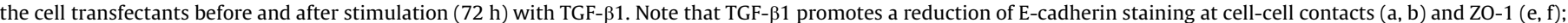

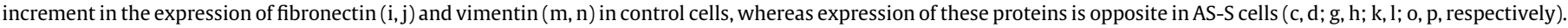

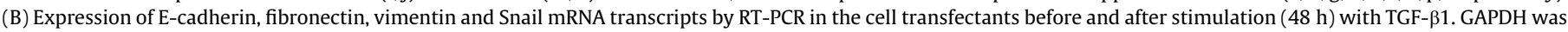

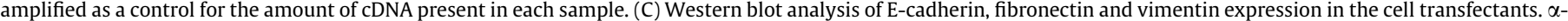
Tubulin was used as a control of protein loading.

in Fig. 4A, stimulation of uPA production by TGF- $\beta 1$ was strongly inhibited in AS-S cells; this result paralleled that obtained by RTPCR analysis (Fig. 4B). Additionally, AS-S cells expressed less uPA receptor after TGF- $\beta 1$ treatment than control cells.

TGF- $\beta 1$ is a potent inductor of plasminogen activator type-1 [1], and the balance between PAI- 1 and uPA regulates the capacity of tumour cells to migrate and invade surrounding tissues [17]. As shown in Fig. 4B, AS-S had an enhanced basal level of PAI-1 mRNA production, which is slightly modified by TGF- $\beta 1$, and reaches the level of PAI- 1 expression in control cells after TGF- $\beta 1$ treatment. Furthermore, a high transcriptional activity, near to that induced by TGF- $\beta 1$ in control cells, of the PAI- 1 promoter (p800-luc) in AS-S cells is observed in basal conditions, and was further increased after TGF- $\beta 1$ treatment.

\section{Discussion}

Given that TGF- $\beta 1$ stimulates the epithelial mesenchymal transition (EMT) and invasiveness in tumoral cells [1,2], it is important to discover which mechanisms control the intracellular signalling of this factor in transformed cells. In addition, the SKIP has been proven to modulate Smads' activities in TGF- $\beta 1$ signaling pathway [6].

PDV cells originate from mouse skin chemical carcinogenesis model, which upon subcutaneous injection produce well differentiated epithelial tumours resembling squamous carcinoma grade II [18]. The mouse skin chemical carcinogenesis model greatly contributed in understanding cancer as a multi-stage tumour progression [18]. In vitro, PDV treatment with TGF- $\beta 1$ triggers the EMT [15], concomitantly with the enhancement of cell migration/invasion and production of extracellular matrix degrading proteins such as uPA and MMP-9 [13,14]. Considering these facts, PDV cells represent a cellular tool convenient for the analysis of the molecular and biochemical mechanisms involved in TGF- $\beta 1$-induced EMT and tumour progression of epithelial cancer cells.

In the current study, we demonstrated that TGF- $\beta 1$ increases SKIP expression in transformed PDV keratinocytes, while SKIP depletion in these cells, introduced by antisense strategy, de- 
A

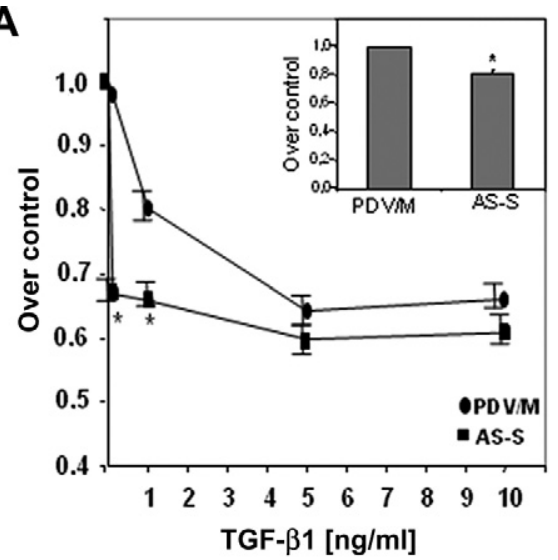

C

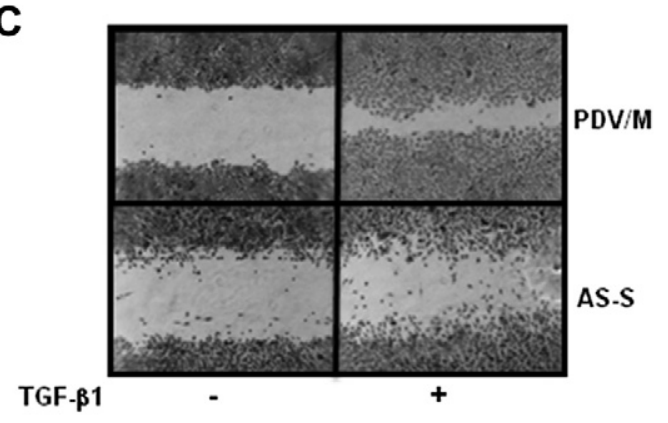

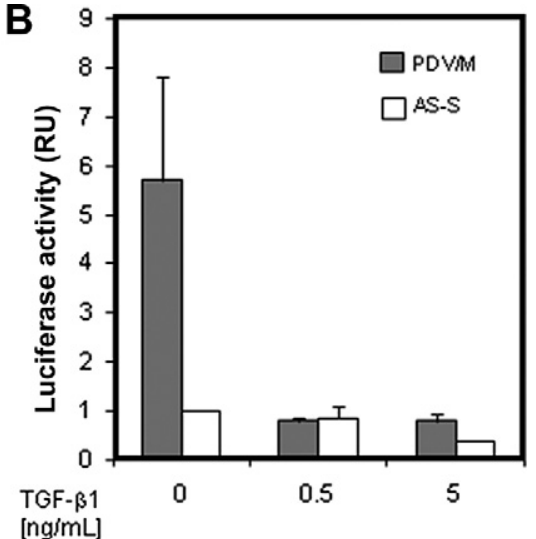

D

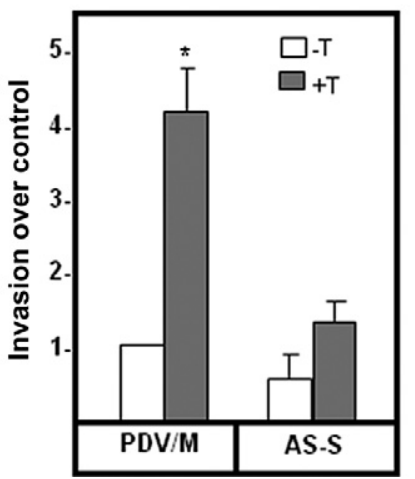

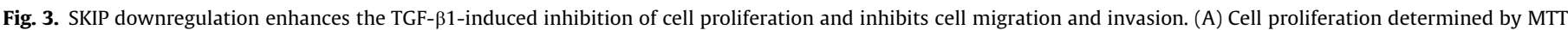

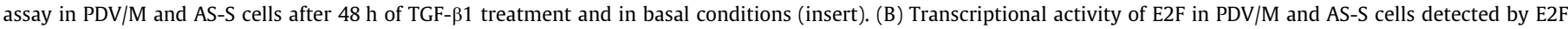

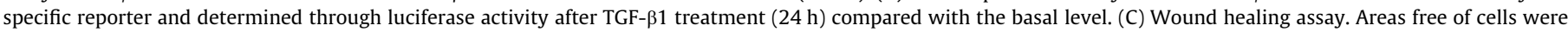

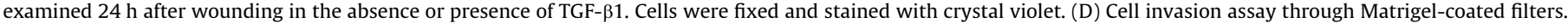
The percentage of migrated cells was calculated in respect to the total number of viable cells at the end of the incubation period ( 3 days).

creases Smad3 activation by TGF- $\beta 1$ (Fig. 1 ). The results obtained are in agreement with previously reported by Leong et al. [6]; however, the role of SKIP in the TGF- $\beta 1$-induced cell malignity was not further explored by this group.

Depletion of SKIP in PDV cells produced an inhibition of TGF$\beta 1$-induced EMT (Fig. 2). Even though the precise mechanism which involves SKIP in the induction of EMT by TGF- $\beta 1$ is unknown, it is likely that it might be mediated through modulating Smad3 activation, since Smad3 has been reported as a critical component in the induction of EMT by TGF- $\beta 1$ [19]. Our findings show that AS-S cells neither downregulate the epithelial markers E-cadherin and ZO-1 nor increase the expression of mesenchymal markers, fibronectin and vimentin, in response to TGF- $\beta 1$. Also, the expression of Snail, a Smad3-dependent immediate-early gene and a potent repressor of E-cadherin expression during EMT $[16,20]$, was inhibited in AS-S cells impeding the downregulation of E-cadherin by TGF- $\beta 1$. Furthermore, the inhibition of Smad3 in PDV cells disabled Snail induction by TGF- $\beta 1$ (data not shown). In the light of previous results showing that fibronectin expression is mediated by Smad3 [21], our results propose that SKIP might cooperate with Smad3 in the induction of fibronectin expression by TGF- $\beta 1$ in PDV cells. To complete EMT epithelial cells acquire a mesenchymal cytoskeleton expressing vimentin [2], which is dependent on Smad3 in cooperation with AP1 and Sp1 transcription factors [22]. Low activation of Smad3 in AS-S cells hindered cells to display the EMT in response to TGF- $\beta 1$. Thus, these results suggest that during TGF- $\beta 1$-induced EMT an increment of SKIP is necessary to consolidate the phenotypical changes, in part by enhancing Smad3 signal transduction. Furthermore, it is known that Smad3 $-/-$ knockout mice are resistant to the induction of skin chemical carcinogenesis [23], as well as that Smad3 largely regulates EMT [18].

Moreover, TGF- $\beta 1$ is a potent inhibitor of cell proliferation in the early steps of tumor progression [1], and the augmentation of SKIP expression could be responsible for cells' resistance to the inhibition of proliferation at low amounts of TGF- $\beta 1$. SKIP has been shown to release cells from G1 arrest induced by Rb (retinoblastoma protein) facilitating cell proliferation [10], whereas TGF- $\beta 1$ maintains $\mathrm{Rb}$ hypophosphorylated during cell cycle arrest in early G1 phase [24]. Results given here showing a slower cell proliferation of AS-S cells compared to PDV parental cells (Fig. 3A, insert), are well correlated with a reduced E2F transactivity in SKIP depleted cells in the absence of exogenous TGF- $\beta 1$ (Fig. 3B). Since it has been suggested that SKIP preferentially binds hypophosphorylated $\mathrm{Rb}$ [10], the reduced level of SKIP in AS-S may enhance the $\mathrm{Rb} / \mathrm{E} 2 \mathrm{~F}$ complex formation in basal conditions, resulting in lower transactivation of E2F, as demonstrated by our results. Both AS-S and control cells respond similarly to the inhibition of E2F transactivity by TGF- $\beta 1$ treatment (Fig. 3B), indirectly suggesting that increased sensitivity to inhibition of cell proliferation by TGF- $\beta 1$ observed in AS-S is independent of $\mathrm{Rb} / \mathrm{E} 2 \mathrm{~F}$ complex induction by the growth factor and that other cell cycle inhibitors (such as p21) might be involved. It is necessary to perform further analyses in order to determine the exact mechanism which implicates SKIP in TGF- $\beta 1$ effect on cell proliferation. SKIP perhaps counteracts the effect of TGF- $\beta 1$ changing the cell response to the growth factor. This is an important point, since during tumour progression, cells acquire resistance to the inhibition of proliferation by TGF- $\beta 1$ $[1,2]$ resulting in tumour growth, a process in which SKIP might have a significant role. 

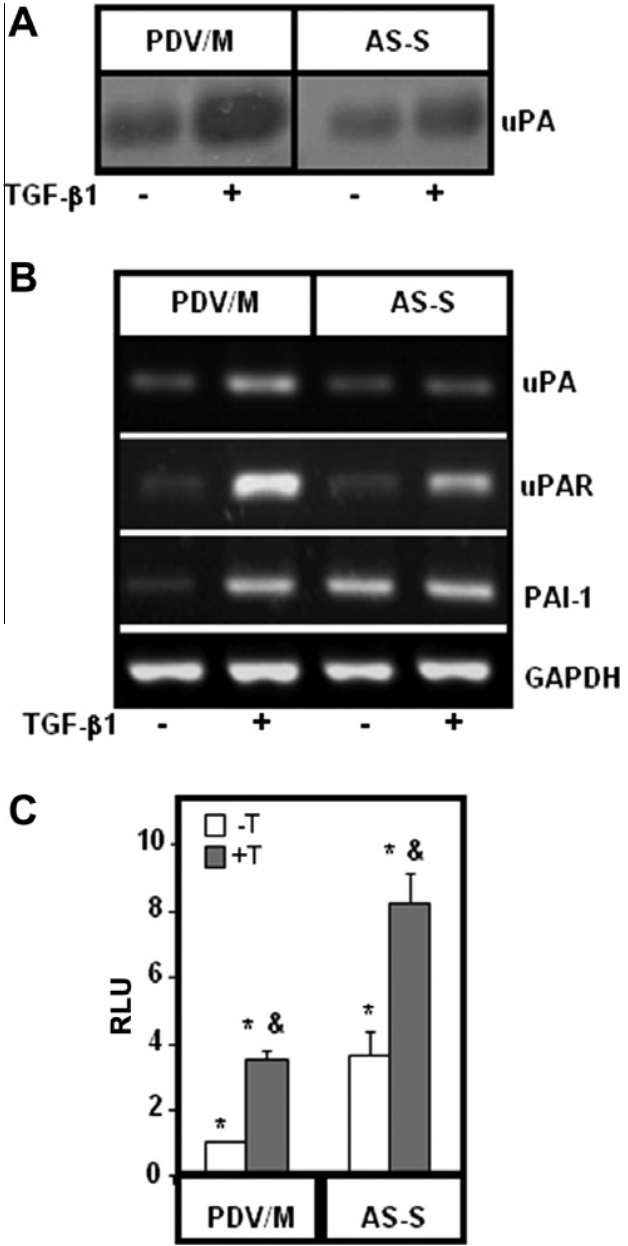

Fig. 4. SKIP depletion alters TGF- $\beta 1$-induced urokinase type plasminogen activator and Plasminogen activator inhibitor type-1 expression. (A) uPA activity was determined by casein-plasminogen-zymography in the serum-free conditioned media of cell transfectants untreated or treated with TGF- $\beta 1$ for $48 \mathrm{~h}$. The activity of uPA produced a clear band in the gel by activating plasminogen. (B) Expression of UPA, uPAR and PAI-1 mRNA transcripts by RT-PCR in the cell transfectants before and after stimulation ( $24 \mathrm{~h}$ ) with TGF- $\beta 1$. GAPDH was amplified as a control for the amount of cDNA present in each sample. (C) Transactivation of PAI-1 promoter in PDV/M and AS-S cells. PAI-1 promoter activity was assayed in cells unstimulated and stimulated with TGF- $\beta 1$ for $48 \mathrm{~h}$ as luciferase inducible activity. $\beta$-Galactosidase was used as an internal control of transfection. RLU, relative luciferase units.

Cell migration is an early cell response to TGF- $\beta 1$ critical for the invasion capacity of cancer cells [1]. Our findings show that SKIP expression is necessary for the cell migration and Matrigel invasion induced by TGF- $\beta 1$. The capacity of cell motility, in part, is related with the expression of proteinase system which allows cells to degrade extracellular matrix [25]. We have previously reported that TGF- $\beta 1$ induces uPA in PDV cells [26], and the results presented in this work introduce SKIP as a significant factor for TGF$\beta 1$-induction of UPA and its receptor (UPAR). Although it is not yet established if SKIP modulates TGF- $\beta 1$-induced uPA/uPAR expression by downregulating Smad3, we are suggesting this as one possibility regarding a recent work which reported Smad4 as a mediator of uPA expression [27].

The activity of UPA is regulated by the expression of PAI-1 [28]. Surprisingly, downregulation of SKIP enhanced the production of PAI-1 in contrast with the inhibition of Smad3 signaling. One conceivable explanation could be the role of SKIP on retinoblastoma inhibition. In hypophosphorylated state $\mathrm{Rb}$ is in complex with $\mathrm{E} 2 \mathrm{~F}$, a cell cycle regulator, whereas when $\mathrm{Rb}$ is phosphorylated by CDKs E2F is released and in free form acts as an inhibitor of
PAI-1 expression [29]. Low expression of SKIP in AS-S cells may keep $\mathrm{Rb} / \mathrm{E} 2 \mathrm{~F}$ in complex, and decrease the transcriptional activity of E2F as is observed in Fig. 3B, which could then result in an increment of PAI-1 expression independent of TGF- $\beta 1$ stimulation. The tuning of $\mathrm{uPA} / \mathrm{uPAR} / \mathrm{PAI}-1$ balance is crucial for cell migration and invasion [17], and SKIP appears to be a key factor for a feasible expression of these proteins allowing efficient migration. The downregulation of SKIP produces an imbalance of this ratio in inhibitory status of uPA system by enhancing PAI-1 and blocking TGF- $\beta 1$-induced uPA/uPAR.

SKIP downregulation is sufficient to modify the cell's response to TGF- $\beta 1$, which might be related with the alteration of Smad3 activation by the growth factor, and the modification in cell signal homeostasis changes the capacity of TGF- $\beta 1$ to induce EMT and cell migration. In addition, no significant changes were found in TGF$\beta 1$-induced ERK1,2 activation, a MAPK signalling involved in TGF$\beta 1$-induced EMT [30] (data not shown). Due to the fact that TGF$\beta 1$ uses a plethoric range of intracellular signaling pathways to enhance cell malignance, such as JNK, NFKB and Rho GTpases $[1,5,13]$, it remains to be resolved whether these pathways, beyond Smad3, are affected by SKIP depletion in PDV cells, and if they also may be involved in TGF- $\beta 1$-induced EMT and cell migration. Although signals other than Smad3 may be altered by changes in SKIP expression, our findings propose that SKIP is an essential factor for TGF- $\beta 1$-induced cell malignance, which suggests SKIP as a possible target for the tumour growth and cancer dissemination control. Also, additional studies in other EMT cellular models as well as in vivo may help in completing a general picture of the role of SKIP in TGF- $\beta 1$-induced EMT.

In conclusion, the data presented here show that SKIP is required for the induction of EMT and the enhancement of cell malignance by TGF- $\beta 1$ in PDV transformed cells.

\section{Conflicts of interest statement}

None to declare.

\section{Acknowledgment}

This work was supported by grants FONDECYT \#1050476, Chile and \#175062 from The Ministry of Science and Technological Development, Republic of Serbia.

\section{References}

[1] Padua, D. and Massagué, J. (2009) Roles of TGFbeta in metastasis. Cell Res. 19, 89-102.

[2] Xu, J., Lamouille, S. and Derynck, R. (2009) TGF-beta-induced epithelial to mesenchymal transition. Cell Res. 19, 156-172.

[3] Derynck, R., Akhurs, T.R.J. and Balmain, A. (2001) TGF-beta signaling in tumor suppression and cancer progression. Nat. Genet. 29, 117-129.

[4] Massague, J. (2008) TGFbeta in cancer. Cell 134, 215-230.

[5] Derynck, R. and Zhang, Y.E. (2003) Smad-dependent and Smad-independent pathways in TGF-beta family signalling. Nature $425,577-584$.

[6] Leong, G.M., Subramaniam, N., Figueroa, J., et al. (2001) Ski-interacting protein interacts with Smad proteins to augment transforming growth factor-betadependent transcription. J. Biol. Chem. 276, 18243-18248.

[7] Dahl, R., Wani, B. and Hayman, M.J. (1998) The Ski oncoprotein interacts with SKIP, the human homolog of Drosophila Bx42. Oncogene 16, 1579-1586.

[8] MacDonald, P.N., Dowd, D.R., Zhang, C. and Gu, C. (2004) Emerging insights into the coactivator role of NCoA62/SKIP in vitamin D-mediated transcription. J. Steroid Biochem. Mol. Biol. 89-90, 179-186.

[9] Folk, P., Puta, F. and Skruzny, M. (2004) Transcriptional coregulator SNW/SKIP: the concealed tie of dissimilar pathways. Cell. Mol. Life Sci. 61, 629-640.

[10] Prathapam, T., Kühne, C. and Banks, L. (2002) SKIP interacts with the retinoblastoma tumor suppressor and inhibits its transcriptional repression activity. Nucleic Acids Res. 30, 5261-5268.

[11] Syed, V., Zhang, X., Lau, K.M., et al. (2005) Profiling estrogen-regulated gene expression changes in normal and malignant human ovarian surface epithelial cells. Oncogene 24, 8128-8143.

[12] Blanco, F.J., Santibanez, J.F., Guerrero-Esteo, M., Langa, C., Vary, C.P. and Bernabeu, C. (2005) Interaction and functional interplay between endoglin 
and ALK-1, two components of the endothelial transforming growth factorbeta receptor complex. J. Cell. Physiol. 204, 574-584.

[13] Santibañez, J.F. (2006) JNK mediates TGF-beta1-induced epithelial mesenchymal transdifferentiation of mouse transformed keratinocytes. FEBS Lett. 580, 5385-5391.

[14] Santibáñez, J., Guerrero, J., Quintanilla, M., Fabra, A. and Martínez, J. (2002) Transforming growth factor-beta1 modulates matrix metalloproteinase-9 production through the Ras/MAPK signaling pathway in transformed keratinocytes. Biochem. Biophys. Res. Commun. 296, 267-273.

[15] Caulín, C., Scholl, F., Frontelo, P., Gamallo, C. and Quintanilla, M. (1995) Chronic exposure of cultured transformed mouse epidermal cells to transforming growth factor-beta 1 induces an epithelial-mesenchymal transdifferentiation and a spindle tumoral phenotype. Cell Growth Differ. 6, 1027-1035.

[16] Cano, A., Pérez-Moreno, M.A., Rodrigo, I., et al. (2000) The transcription factor snail controls epithelial-mesenchymal transitions by repressing E-cadherin expression. Nat. Cell Biol. 2, 76-83.

[17] Andreasen, P.A., Kjøller, L., Christensen, L. and Duffy, M.J. (1997) The urokinase-type plasminogen activator system in cancer metastasis: a review. Int. J. Cancer. 72, 1-22.

[18] Zoumpourlis, V., Solakidi, S., Papathoma, A. and Papaevangeliou, D. (2003) Alterations in signal transduction pathways implicated in tumour progression during multistage mouse skin carcinogenesis. Carcinogenesis 24, 1159-1165.

[19] Roberts, A.B., Tianm, F., Byfield, S.D., et al. (2006) Smad3 is key to TGF-betamediated epithelial-to-mesenchymal transition, fibrosis, tumor suppression and metastasis. Cytokine Growth Factor Rev. 7, 19-27.

[20] Yang, Y.C., Piek, E., Zavadil, J., et al. (2003) Hierarchical model of gene regulation by transforming growth factor-beta. Proc. Natl. Acad. Sci. U.S.A. 100, 10269-10274.

[21] Ryer, E.J., Hom, R.P., Sakakibara, K., et al. (2006) PKCdelta is necessary for Smad3 expression and transforming growth factor beta-induced fibronectin synthesis in vascular smooth muscle cells. Arterioscler. Thromb. Vasc. Biol. 26, 780-786.

[22] Wu, Y., Zhang, X., Salmon, M., Lin, X. and Zehner, Z.E. (2007) TGFbeta1 regulation of vimentin gene expression during differentiation of the $\mathrm{C} 2 \mathrm{C} 12$ skeletal myogenic cell line requires Smads, AP-1 and Sp1 family members. Biochim. Biophys. Acta 1773, 427-439.

[23] Li, A.G., Lu, S.L., Zhang, M.X., Deng, C. and Wang, X.J. (2004) Smad3 knockout mice exhibit a resistance to skin chemical carcinogenesis. Cancer Res. 64 7836-7845.

[24] Laiho, M., DeCaprio, J.A., Ludlow, J.W., et al. (1990) Growth inhibition by TGF- $\beta$ linked to suppression of retinoblastoma protein phosphorylation. Cell 62 175-185.

[25] Liotta, L.A. and Kohn, E.C. (2001) The microenvironment of the tumour-host interface. Nature 411, 375-379.

[26] Santibáñez, J.F., Iglesias, M., Frontelo, P., Martínez, J. and Quintanilla, M. (2000) Involvement of the Ras/MAPK signaling pathway in the modulation of urokinase production and cellular invasiveness by transforming growth factor-beta(1) in transformed keratinocytes. Biochem. Biophys. Res. Commun. 273, 521-527.

[27] Shiou, S.R., Datta, P.K., Dhawan, P., Law, B.K., et al. (2006) Smad4-dependent regulation of urokinase plasminogen activator secretion and RNA stability associated with invasiveness by autocrine and paracrine transforming growth factor-beta. J. Biol. Chem. 281, 33971-33981.

[28] Samarakoon, R. and Higgins, P.J. (2008) Integration of non-SMAD and SMAD signaling in TGF-beta1-induced plasminogen activator inhibitor type-1 gene expression in vascular smooth muscle cells. Thromb. Haemost. 100, 976-983.

[29] Koziczak, M., Krek, W. and Nagamine, Y. (2000) Pocket protein independent repression of urokinase-type plasminogen activator and plasminogen activator inhibitor 1 gene expression by E2F1. Mol. Cell. Biol. 20, 2014-2022.

[30] Xie, L., Law, B.K., Chytil, A.M., Brown, K.A., Aakre, M.E. and Moses, H.L. (2004) Activation of the Erk pathway is required for TGF-beta1-induced EMT in vitro. Neoplasia 6, 603-610. 